\title{
GPS and GSM based Vehicle Tracing and Employee Security System
}

\author{
S.S.Pethakar \\ Bharati Vidyapeeth Unv.Pune \\ Pune-Satara road Pune 411043
}

\author{
N. Srivastava \\ Bharati Vidyapeeth Unv.Pune \\ Pune-Satara road Pune 411043
}

\author{
S.D.Suryawanshi \\ Bharati Vidyapeeth Unv.Pune \\ Pune-Satara road Pune 411043
}

\begin{abstract}
A GPS \& GSM Based Vehicle Tracking and Employee Security System combine the installation of an electronic device in a vehicle, with purpose-designed computer software to enable the company to track the vehicle's location. In vehicle tracking systems we use Global Positioning System (GPS) technology for locating the vehicle. Vehicle information can be viewed on electronic maps via the Internet or specialized software. Due to recently happened mishaps such as burglary, rape cases etc., the employee safety, esp. for the women employees, has become a number one priority for most of the companies. Even though the companies take good precautions to ensure that its employees are safe, there are some serious loop holes in the existing system. Firstly there is no full proof mechanism to track the outsiders to avoid this kind of problem we are going to implement a system that provides more security to the employee. The car Unit is placed inside the car. When the car picks up the employee; he/she needs to swap the RFID card. The micro controller matches the RFID card no. with its database records and sends the employee's id, cab id \& the cab position co-ordinates to the company unit via GSM module. The GSM Modem will receive the message through GSM in the company unit. If employee finds himself/herself in a problem, he/she will press the button. Microcontroller will detect the action \& sends a signal to the GSM which will coordinate with to the company unit and police. Microcontroller will also send a signal to the relay which will turn off the car ignition \& stop the car. The GSM Modem will receive the message. This message will then be transferred to the computer through the serial port. The employee name, employee id \& cab position coordinates (longitude and latitude) get displayed on computer. Once the data is obtained on the computer, it can be used for further analysis. In this way the company unit keeps a track of the vehicle. This will be a much simpler and low cost technique compared to others.
\end{abstract}

\section{Keywords}

Global Positioning System (GPS), Global system for mobile (GSM), Radio-frequency identification (RFID)

\section{INTRODUCTION}

In today's world, security is a very important aspect for the working professionals. It is the company's utmost responsibility to take care of its employee's safety.

In the last few decades, India has progressed at such an enormous rate that many companies have strongly established themselves here. These companies bring a huge amount of workforce with them. Arranging transportation to such a huge mass is a cumbersome task involving lots of intricacies.
Generally this conveyance facility is arranged through the local transport vendors on a yearly contract basis.

Due to recently happened mishaps such as burglary, rape cases etc., the employee safety, esp. for the women employees, has become a number one priority for most of the companies. Even though the companies take good precautions to ensure that its employees are safe, there are some serious loop holes in the existing system. Firstly there is no full proof mechanism to track the outsiders. The drivers of the cabs cannot be trusted. There exists no system to communicate and track the vehicle in danger on most of the vehicles.

In order to deal with these problems, we have come up with the innovative solution of "GPS \& GSM Vehicle Tracking and Employee Security System". This system will detect the outsiders as well as locate the cabs through RFID \& GPS mechanisms. We have also incorporated an emergency button for employee's safety. Wherever an employee finds himself/herself in trouble, he/she will press the button and an SMS will be sent to the nearest police station and the company's monitoring unit, so that they will take the necessary action.

In this project we proposed GSM \& GPS based system for Vehicle Tracking and Employee Security System. It consists of car unit, emergency button and company unit. Car unit is placed inside the car. When the car picks up the employee; he/she needs to swap the RF card. The micro controller matches the RF card no. with its database records and sends the employee's id, cab id \& the cab position co-ordinates to the company unit via GSM module. Emergency button is a part of car unit. There are three to four emergency buttons in the car. These buttons are placed at such position so that employee can access them easily i.e. near the door unlocking handle. If employee finds himself/herself in a problem, he/she will press the button. Microcontroller will detect the action \& sends a signal to the GSM which will coordinate with to the company unit and police. Microcontroller will also send a signal to the relay which will turn off the car ignition \& stop the car. Company unit consists of GSM modem, RS232 cable \& computer. The GSM Modem will receive the message through GSM. This message will then be transferred to the computer through the serial port. The employee name, employee id \& cab position coordinates (longitude and latitude) get displayed on computer.

\section{OVERVIEW OF THE SYSTEM}

In this project we proposed GSM \& GPS based system for Vehicle Tracking and Employee Security System. It consists of car unit, emergency button and company unit. Car unit is placed inside the car. When the car picks up the employee; he/she needs to swap the RF card. The micro controller matches the RF card no. with its database records and sends 
the employee's id, cab id \& the cab position co-ordinates to the company unit via GSM module. Emergency button is a part of car unit. There are three to four emergency buttons in the car. These buttons are placed at such position so that employee can access them easily i.e. near the door unlocking handle. If employee finds himself/herself in a problem, he/she will press the button. Microcontroller will detect the action \& sends a signal to the GSM which will coordinate with to the company unit and police. Microcontroller will also send a signal to the relay which will turn off the car ignition \& stop the car. Company unit consists of GSM modem, RS232 cable \& computer. The GSM Modem will receive the message through GSM. This message will then be transferred to the computer through the serial port. The employee name, employee id \& cab position coordinates (longitude and latitude) get displayed on computer. The visual basic software reads the co-ordinates and displays the vehicle location. In this way the company unit keeps a track of the vehicle.[4]

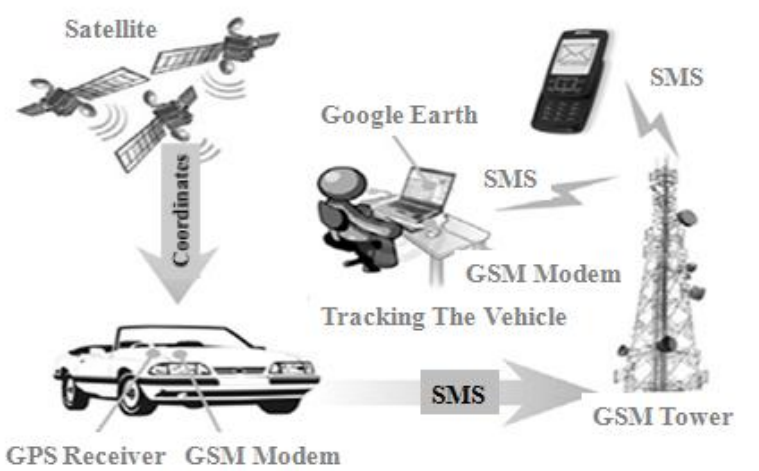

Fig. 1: The block diagram of Security system

As shown in Fig. 1 the tracking device which is attached to the moving automobile. This module composes of: a GPS receiver, Microcontroller and a GSM Modem. The GPS Receiver retrieves the location information from satellites in the form of latitude and longitude real-time readings. The Microcontroller has two main tasks: to processes the GPS information to extract desired values and to transmit this data to the server using GSM modem by SMS.

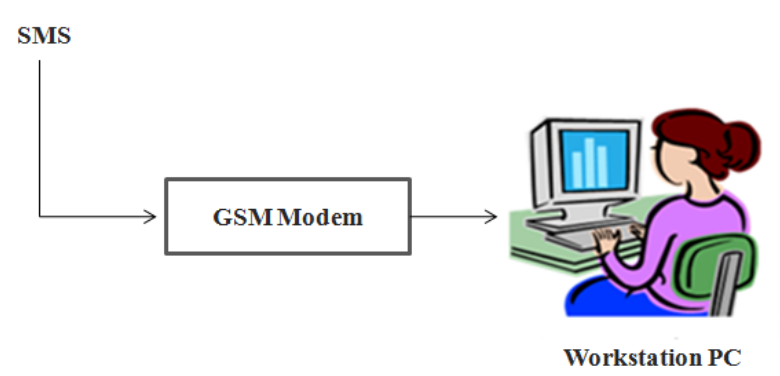

Fig. 2: The system architecture

Fig. 2 shows a recipient GSM modem and workstation PC. The modem receives the SMS that includes GPS coordinates and employee id, cab id information. This text is processed using a Visual Basic program to obtain the numeric parameters, which are saved as a Microsoft Office Excel file. The received reading of the GPS is further corrected by Kalman filter. To transfer this information to Google Earth, the Excel file is converted to KML (Keyhole Markup Language) format. Google Earth interprets KML file and shows automobile's location and engine parameters on the map. The system's efficiency is dependable on the sufficiency of the used communication network.

\section{PROPOSED SYSTEM}

The entire system is divided into three parts. Car unit Emergency Button, Company unit

\subsection{Car unit description}

Fig.3 shows block diagram of car unit. This Unit is placed inside the car. When the car picks up the employee; he/she needs to swap the RF card. The micro controller matches the RF card no. with its database records and sends the employee's id, cab id \& the cab position co-ordinates to the company unit via GSM module.

\subsubsection{RFID Card}

When the car picks up the employee; he/she needs to swap the RF card. The micro controller matches the RF card no. with its database records and sends the employee's id, cab id \& the cab position co-ordinates to the company unit via GSM module.

\subsubsection{RFID Reader}

Radio frequency identification (RFID) is a generic term that is used to describe a system that transmits the identity (in the form of a unique serial number) of an object or person wirelessly, using radio waves. It's grouped under the broad category of automatic identification technologies.

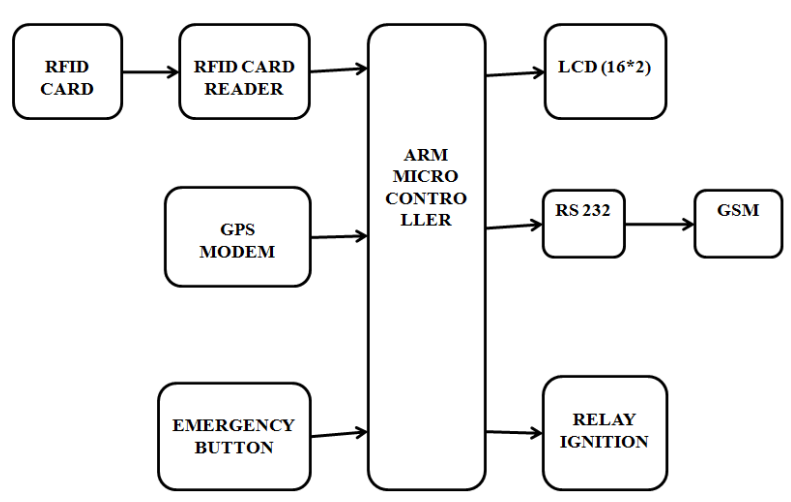

Fig. 3: The block diagram of car unit

\subsubsection{GPS}

GPS which stands for Global Positioning System is a satellite navigation system. It is used to track the car. [1],[6]

\subsubsection{Microcontroller}

It is heart of the system. All the controlling actions are implemented by microcontroller LPC2138 with the help of software program.

\subsubsection{LCD}

It is used to display employee number

\subsubsection{RS232}

RS stands for recommended standard. The project kit is interfaced to computer through serial port. For serial communication RS 232 standard is used. In our project the master is connected to the PC via RS232. That is a clock 
signal is not sent with the data. Each word is synchronized using its start bit, and an internal clock on each side, keeps tabs on the timing. The RS-232 levels are generated internally using switching latches and capacitors of 10uf each.

\subsubsection{GSM}

GSM (Global System for Mobile communication) is a digital mobile telephony system it is use to send the employee's id, cab id \& the cab position co-ordinates to the company unit via GSM module. It also used to the SMS to the police as well as company unit when employee is in emergency.

\subsection{Emergency button}

This is a special facility provided to the employee. Emergency button is a part of car unit. There are three to four emergency buttons in the car. These buttons are placed at such position so that employee can access them easily i.e. near the door unlocking handle. If employee finds himself/herself in a problem, he/she will press the button. Microcontroller will detect the action \& sends a signal to the GSM which will coordinate with to the company unit and police. Microcontroller will also send a signal to the relay which will turn off the car ignition \& stop the car.

\subsection{Company unit}

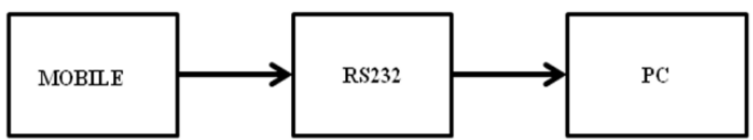

Fig.4: Block Diagram of Company Unit

Fig.4 shows the block diagram of company unit. Company unit consists of GSM modem, RS232 cable \& computer. The GSM Modem will receive the message through GSM. This message will then be transferred to the computer through the serial port. The employee name, employee id \& cab position coordinates (longitude and latitude) get displayed on computer. The visual basic software reads the co-ordinates and displays the vehicle location. Once the data is obtained on the compute, it can be used for further analysis. In this way the company unit keeps a track of the vehicle.

\section{IMPLEMENTATION}

\subsection{Interfacing of RFID with Controller}

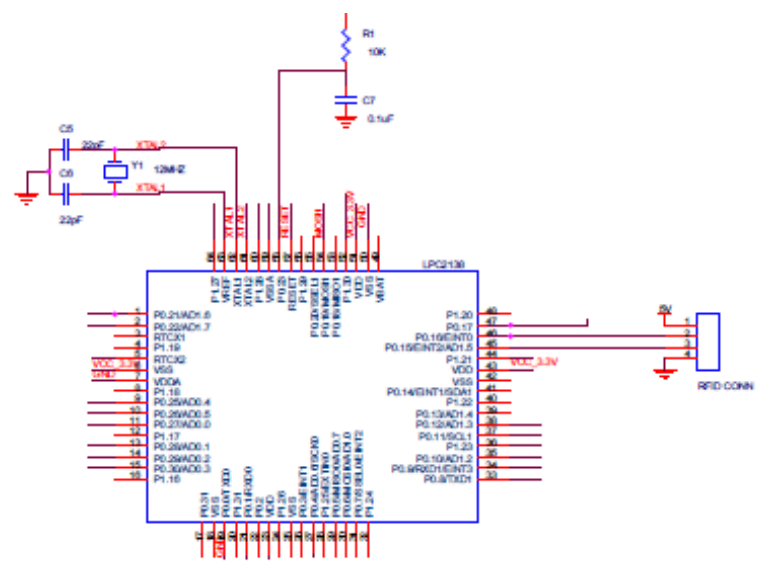

Fig. 5: Interfacing of RFID with Microcontroller
As shown in fig.5 the RF reader comes with the following connections as shown in the diagram above. In this we only connect 4 connections namely VCC, GND, DATA 1, DATA 2.Here the data 1 and data 2 are connected to the interrupt pins of the microcontroller. The Wiegand protocol is an Interrupt based protocol in which the data is given to the microcontroller in the form of interrupts.

\subsection{Interfacing of Emergency button (keypad) with microcontroller}

Fig.6 shows the interfacing of emergency button with microcontroller. It is connect to port 0 . Initially port pin is high. When button is press there is an emergency.

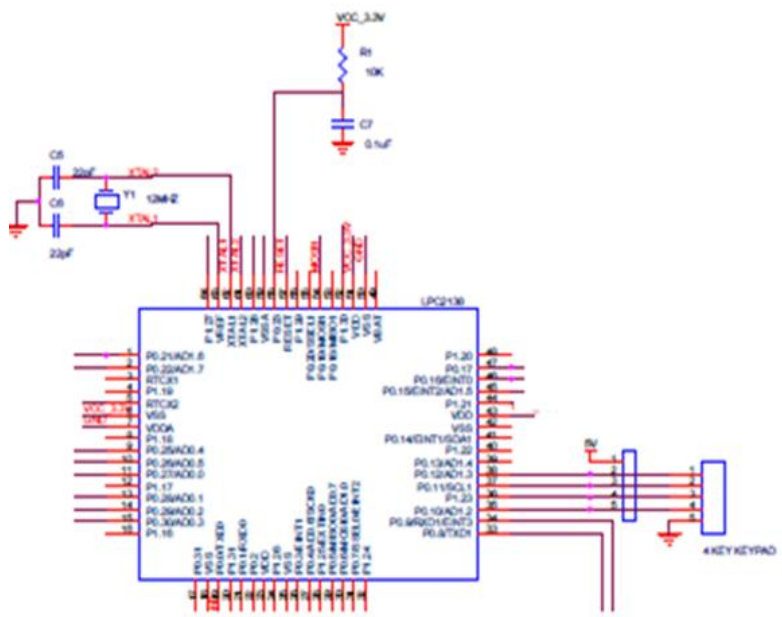

Fig. 6: Interfacing of Emergency button with Microcontroller

\subsection{Interfacing of $\mathrm{RS} 232$ with controller}

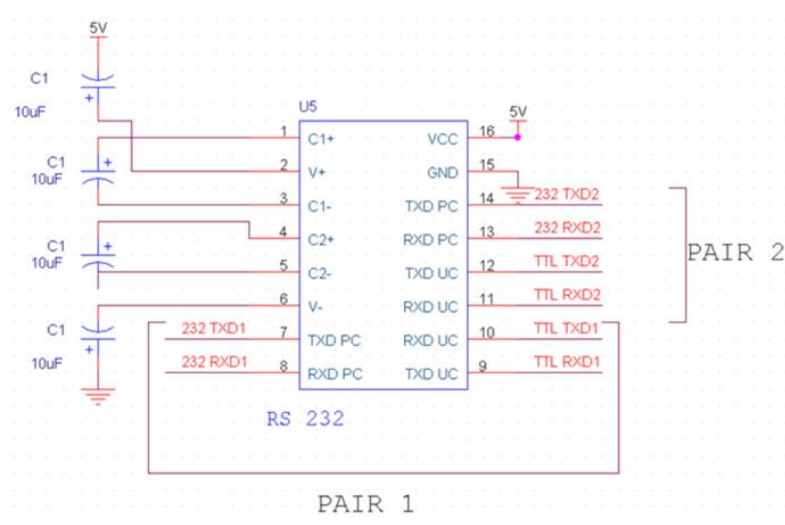

Fig.7: Interfacing of RS 232 with Microcontroller

In Fig.7 we see RS 232 IC is a driver IC to convert the $\mu \mathrm{C}$ TTL logic(0-5) to the RS 232 logic (+-9v).Many device today work on RS 232 logic such as PC, GSM modem, GPS etc. so in order to communicate with such devices we have to bring the logic levels to the $232 \operatorname{logic}(+/-9 \mathrm{v})$. Here as we can see the RS 232 have 2 pairs of TTL and 232 logic, pair 1: Pin 7, $8,9,10$ of RS 232 and Pair 2: pin 11,12,13,14 of RS 232. We can use any one pair in our project either $7,8,9,10$ pair or $11,12,13,14$ pair. If we require 2 serial ports then depending on the requirement of the project we may have to use both the pair in the same project. The microcontroller works on TTL logic $(0-5 \mathrm{v})$.So to convert the TTL logic to RS 232 logic we use the 4 capacitors connected to the RS232 IC. These 
capacitors are called charge pumps used to convert the TTL voltage to the $+/-9 \mathrm{v}$ swing required by the $232 \mathrm{IC}$

\subsection{Interfacing of GPS and GSM with Microcontroller}

Here in our project we have One RS232 through which we can connect 2 pairs of serial Devices .So in our project we have 2 Devices that work on serial VIZ, GSM modem and GPS receiver. So we connect the GPS receiver to the RXD pin of RS 232 as shown and the GSM to the TXD pin of RS 232 .

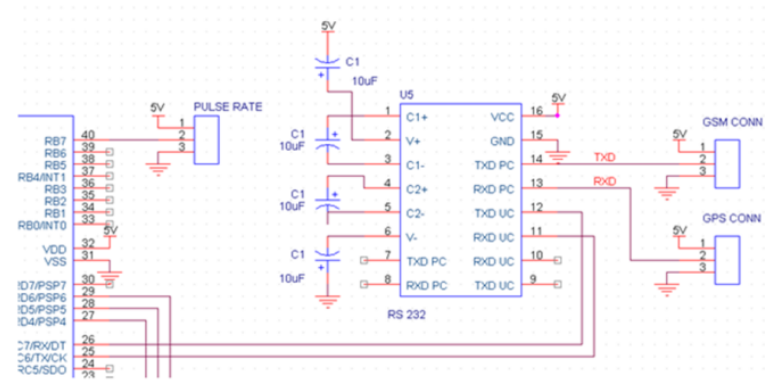

Fig 8: Interfacing of GPS \& GSM with Microcontroller

\subsection{Interfacing of $\mathrm{LCD}$ with controller}

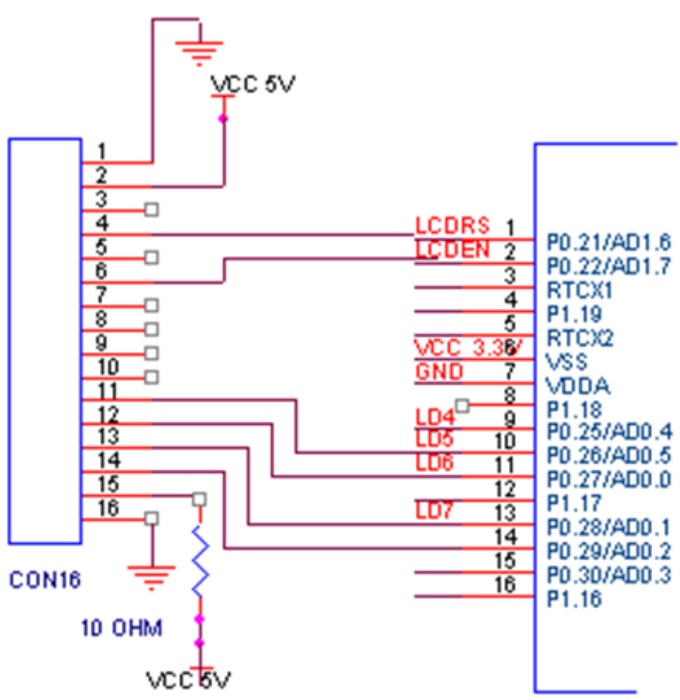

Fig.9: Interfacing of LCD with Microcontroller

LCD has 8 / 4 data lines and 3 control lines. The 4 data lines of LCD (pin 11 to pin 14 of LCD) are connected to port 0 of the $\mu \mathrm{C}(0.26,0.27,0.28,0.29)$. The control lines are LCD RS, LCD R/W, and LCD E. In this we are connecting only 2 lines, viz, LCD E and LCD RS. The LCD RD/WR is grounded, since we only write into the LCD and never read from LCD. These 2 lines are connected to the port $0(0.21$, 0.22) of the ARM micro controller. The LCD RS is for selecting the data or the code register. The LCDR/W is for choosing between reading and writing on LCD. LCDE is for enabling or disabling the LCD

\section{RESULT}

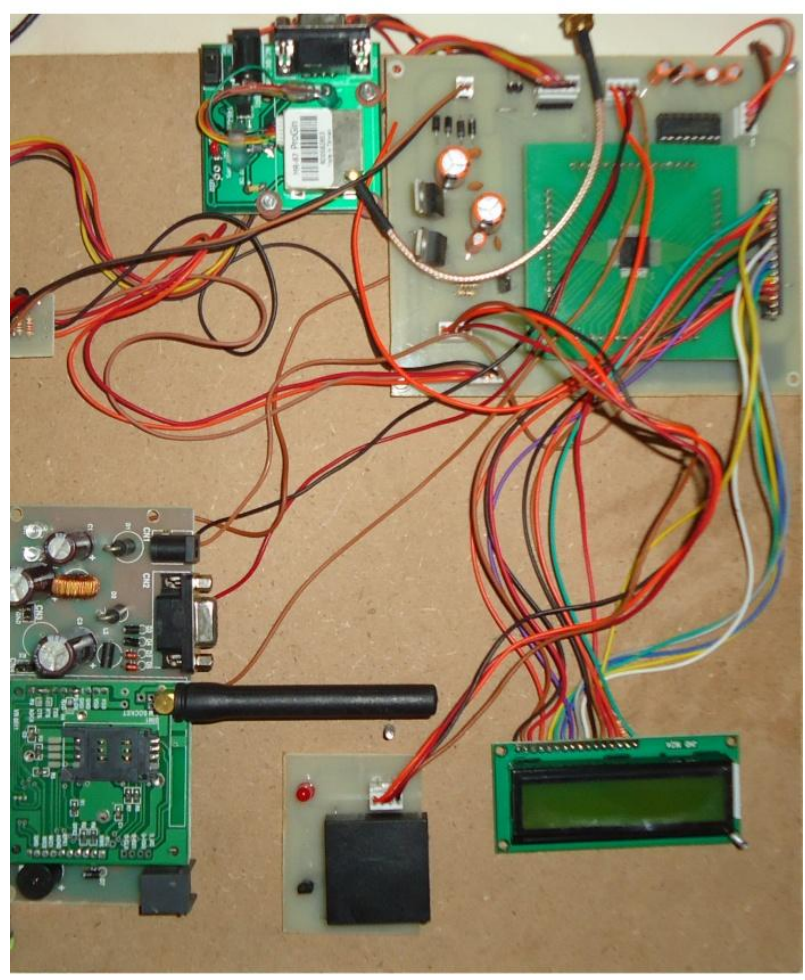

Above picture depicts GSM \& GPS based Vehicle Tracking and Employee Security System. It consists of Microcontroller, GPS unit, Emergency button, Relay unit, GSM unit, RFID Reader; LCD Display.Picture shows car unit which is placed in the car. In the car unit microcontroller is the heart of the system. All the controlling actions are carried out by the microcontroller.

\section{Working of the GSM \& GPS based Vehicle Tracking and Employee Security System}

Step 1: Each driver is having a RFID card which is valid for a specific car only. Before the driver enters the car it is compulsory for the driver to show the card to the RFID UNIT (unit no F). LCD displays the message show card as shown in following picture

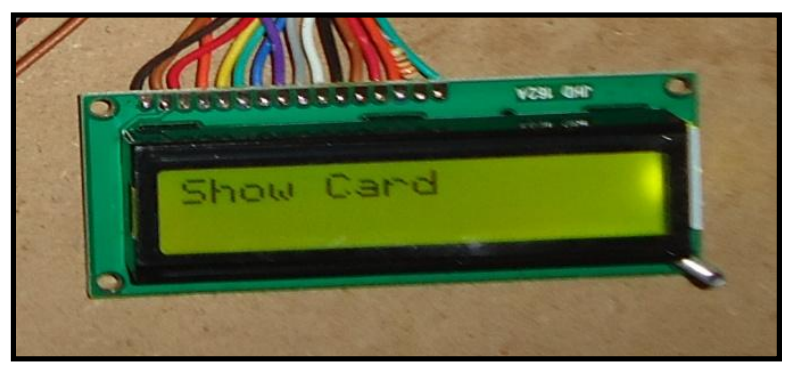

After seeing this message driver shows his RFID card. Then LCD displays following message 


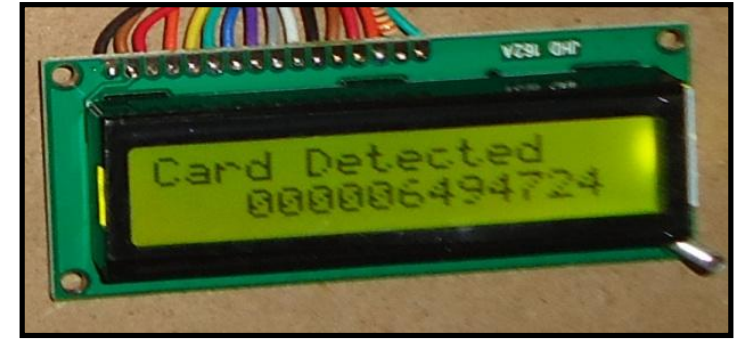

Step 2: If the card is not valid then invalid card message display on the LCD. If the card is valid then valid card message display on the LCD and relay turns on (i.e. car ignition is on). When relay unit is on LED turns on into red colour as shown in following picture. If anyone tries to start the car with an invalid card entry, the system will not allow.

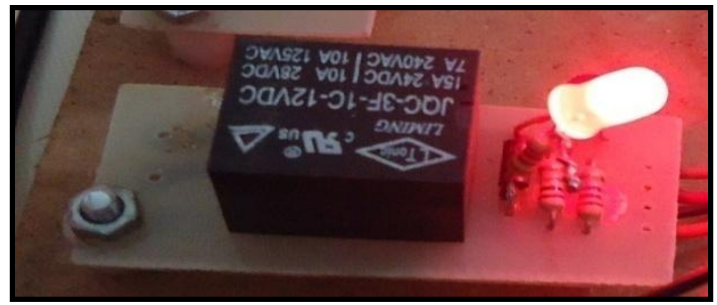

Step 3: When an employee enters the car by showing his/her RFID card, the employee details \& the car position (longitude $\&$ latitude) coordinates will be send to the company unit. The LCD also shows all the details.

The various messages such as position of the car (longitude \& latitude), total employees in the car shown by LCD are as shown below

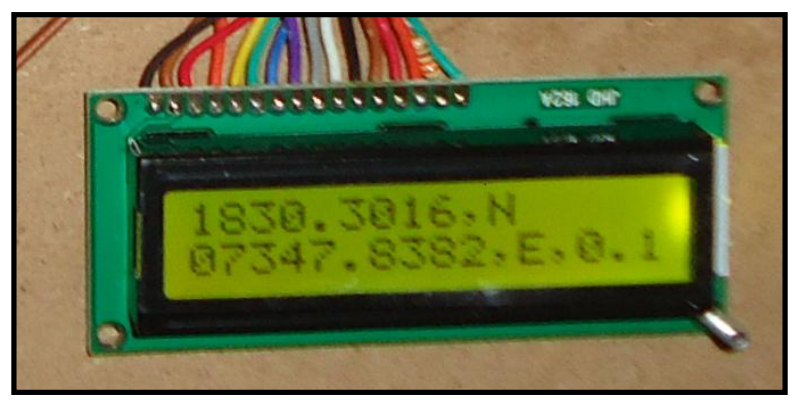

Step 4: If the employee is in unsafe condition, he/she will press the emergency button to stop the car. Following picture shows emergency buttons used in project.

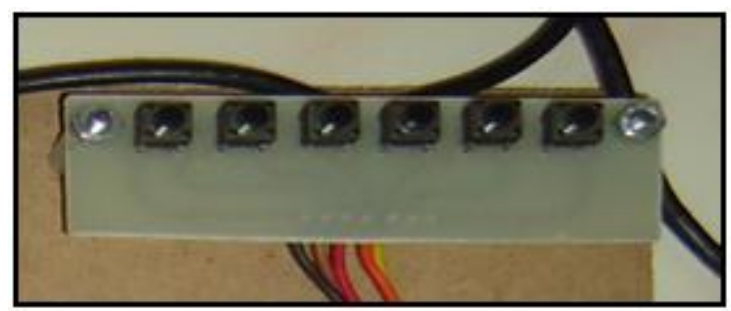

This will immediately turned off the car ignition (relay off) and an SMS will be sent to the company unit. Once turned off, only the base station can start the car (relay on). LCD displays the message sending SMS as shown in following picture

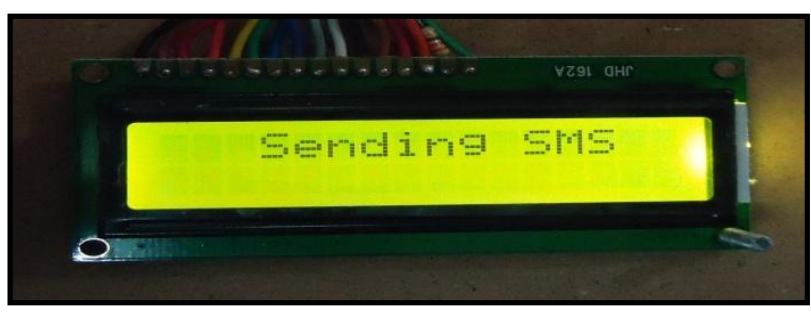

Step 5: Company unit consists of mobile, RS232 cable \& computer. The mobile will receive the message through GSM. This message will then be transferred to the computer through the serial port. The employee name, employee id \& cab position coordinates (longitude and latitude) get displayed on computer. The visual basic software reads the co-ordinates and displays the vehicle location. Once the data is obtained on the compute, it can be used for further analysis. In this way the company unit keeps a track of the vehicle. VB window is as shown in picture

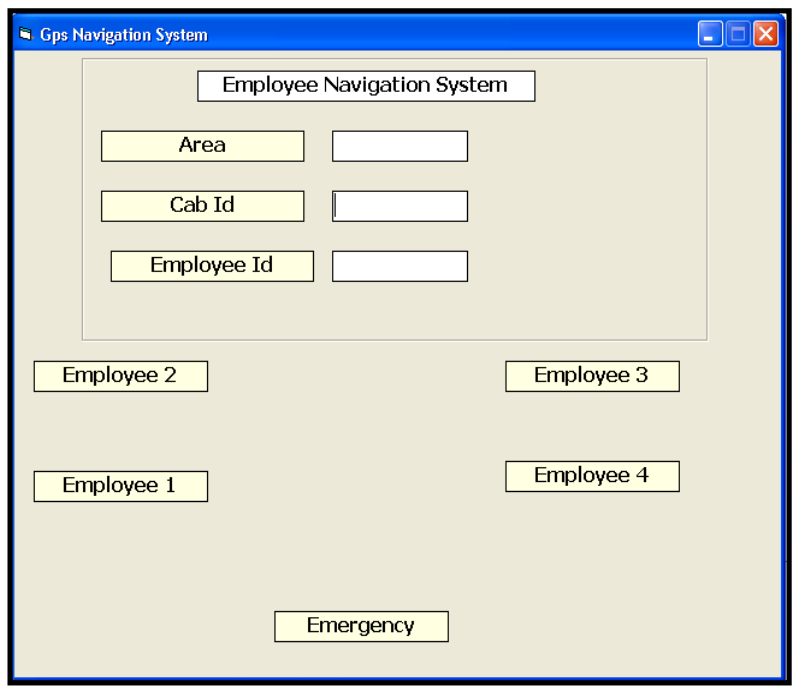

Step 6: To show the tracking of the car; KML file will be created and linked to Google Earth. Based on available coordinates, at each time there is new latitude and longitude update, a point will be placed on Google Earth using KLM format and by having several points, this will allow us to trace the car. Thus, the database can link the GPS Coordinate to Google Earth for real-time tracking. Figure shows the.kml file uploaded in Google Earth with all related information. 


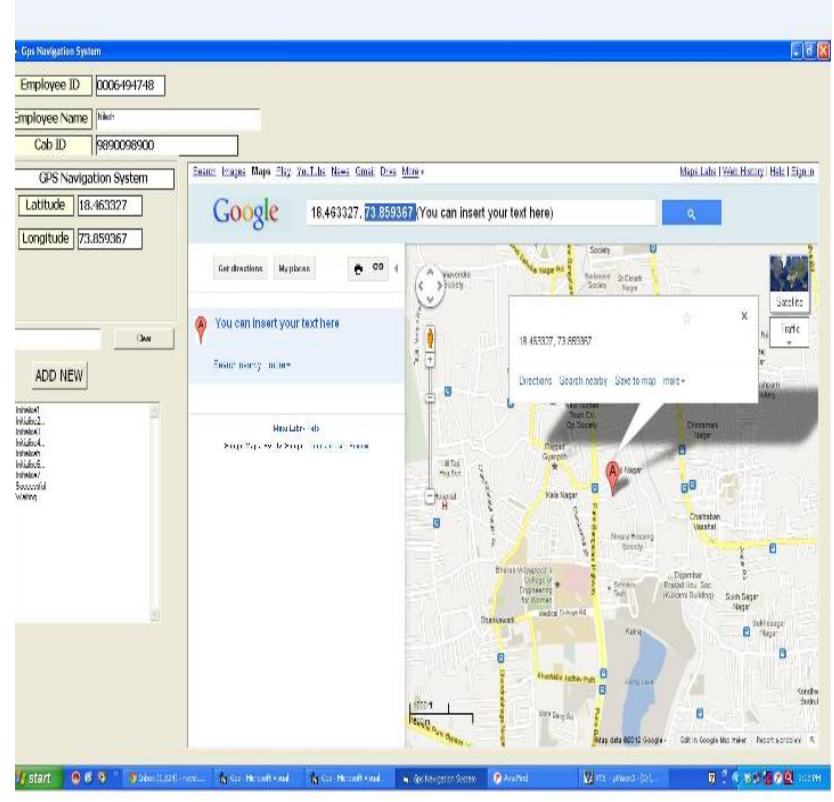

\section{CONCLUSION}

The GSM \& GPS based Vehicle Tracking and Employee Security System is becoming increasingly important in large cities and it is more secured than other systems. Due to recently happened mishaps such as burglary, rape cases etc., the employee safety, esp. for the women employees, has become a number one priority for most of the companies, with this we can have a good control in it. The car can be turned off by only with a simple SMS. The microcontroller is the brain of the system and the GSM modem controlled by AT commands facilitates data transmission over GSM network while the GPS module provides the location data. The system will provide accurate data in a timely manner such that it will enable the security company to know the location of the tracked car and facilitate an early recovery of the tracked car. Implementation of GPS in vehicles can certainly bring a revolutionary impact in transportation science in a developing country like India where there is an extremely high urban as well as rural vehicular transition every day. The system included two main components: a transmitting embedded module to interface in-vehicle GPS and GSM devices in order determine and send automobile location and status information via SMS. The second stationary module is a receiving module to collect and process the transmitted information to a compatible format with Google Earth to remotely monitor the automobile location and status online. We can collect all data such as position of the car, employee information.

\section{ACKNOWLEDGMENTS}

I take this opportunity to express my profound gratitude and deep regards to my guide Professor N. Srivastava for his exemplary guidance, monitoring and constant encouragement throughout the course of this paper. This paper would not have been possible without the guidance and the help of him.

Also, special thanks to my colleague Ms Sonali Suryawanshi. for sharing her knowledge and invaluable assistance.

I would also like to convey my sincere regards to people who knowingly or unknowingly help me during my project.

Last but not the least, I would like to express my love and gratitude to my beloved family for its understanding \& endless love, through the duration of my studies.

\section{REFERENCES}

[1] Mrs.RamyaKulandaivel1, P.Ponmalar2,B.Geetha3, G.Saranya4 "GPS and GSM based vehicle information system" International Journal of Communications and Engineering Volume 01- No.1, Issue: 01 March2012

[2] Deepak Mishra, Apurv Vas, Puneet Tandon "A novel and cost effective approach to public vehicle tracking system" International Journal of UbiComp (IJU), Vol.3, No.1, January 2012

[3] Ruchika Gupta and BVR Reddy "GPS and GPRS Based Cost Effective Human Tracking System Using Mobile Phones" Volume 2 • No. 1 • January-June 2011

[4] Mohammad A. Al-Khedher "Hybrid GPS-GSM Localization of Automobile Tracking System" International Journal of Computer Science \& Information Technology (IJCSIT) Vol 3, No 6, Dec 2011

[5] Francis Enejo Idachaba "Design of a GPS/GSM based tracker for the location of stolen items and kidnapped or missing persons in NIGERIA"ARPN Journal of Engineering and Applied Sciences VOL. 6, NO. 10, OCTOBER 2011

[6] Adnan I. Yaqzan, Issam W. Damaj, and Rached N. Zantout "GPS-based Vehicle Tracking System-on-Chip" Proceedings of the World Congress on Engineering 2008 Vol I WCE 2008, July 2 - 4, 2008, London, U.K.

[7] T. Krishna Kishore, T.Sasi Vardhan, N.Lakshmi Narayana "Vehicle Tracking Using a Reliable Embedded Data Acquisition Sytem With GPS and GSM" IJCSNS International Journal of Computer Science and Network Security, VOL.10 No.2, February 2010 